\title{
Household food insecurity, nutritional status and morbidity in Brazilian children
}

\author{
Muriel Bavermann Gubert ${ }^{1,2, *}$, Ana Maria Spaniol ${ }^{3}$, Gisele Ane Bortolini ${ }^{3}$ and \\ Rafael Pérez-Escamilla ${ }^{2}$ \\ 'Universidade de Brasília, Faculdade de Ciências da Saúde, Departamento de Nutrição, Campus Universitário \\ Darcy Ribeiro, Asa Norte, CEP 70910-900, Brasília, DF, Brazil: ${ }^{2}$ Yale School of Public Health, Department of \\ Chronic Disease Epidemiology, New Haven, CT, USA: ${ }^{3}$ Ministério da Saúde, Coordenação Geral de Alimentação e \\ Nutrição, Brasília, DF, Brazil
}

Submitted 6 July 2015: Final revision received 21 December 2015: Accepted 26 January 2016: First published online 19 February 2016

\begin{abstract}
Objective: To identify the association of household food insecurity (HFI) with anthropometric status, the risk of vitamin A deficiency and anaemia, morbidities such as cough and fever, and hospitalizations for diarrhoea and pneumonia in children under 5 years old.

Design: Cross-sectional study using data from the 2006 Brazilian Demographic and Health Survey. HFI was measured with the Brazilian Food Insecurity Measurement Scale (EBIA). Vitamin A deficiency and anaemia were assessed in blood samples. Child morbidities were reported by the child's mother and included cough, fever, and hospitalizations for diarrhoea and pneumonia. Regression results were expressed as unadjusted and adjusted OR and corresponding 95\% CI for severe food insecurity, with statistical significance set at $P<0.05$.

Setting: Nationally representative survey.

Subjects: Children ( $n$ 4064) under 5 years old.

Results: There was no association between HFI and vitamin A deficiency, pneumonia, wasting or overweight. The prevalence of cough, fever, hospitalization for diarrhoea and stunting were associated with degree of HFI severity. There was a significant association of morbidities and stunting with severe food insecurity ( $v$. food secure). After controlling for confounders, the association between severe food insecurity ( $v$. food secure/rest of food insecurity categories) and the prevalence of common morbidities remained strong, showing that severely food-insecure children had a greater likelihood of experiencing cough (adjusted $\mathrm{OR}=1.79$ ) and of being hospitalized for diarrhoea (adjusted OR $=2.55$ ). Conclusions: Severe HFI was associated with cough and severe diarrhoea among Brazilian children.
\end{abstract}

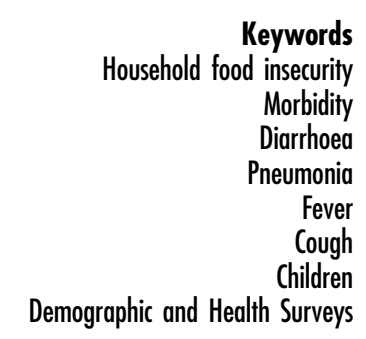

Household food insecurity (HFI) happens when people do not have, at all times, physical, social and economic access to sufficient, safe and nutritious food which meets their dietary needs and food preferences for an active and healthy life ${ }^{(1)}$. HFI is a global epidemic that can lead to hunger and malnutrition. The FAO estimates that 795 million people are undernourished globally ${ }^{(2)}$. In Brazil, only $62.5 \%$ of households are considered food secure and $4.8 \%$ are severely food insecure, a percentage that reaches $5.8 \%$ in households with minors under the age of 18 years ${ }^{(3)}$.

HFI is known to be associated with insufficient or inadequate food intake ${ }^{(4)}$ and this low intake of healthy foods and micronutrients is associated with worse health status $^{(5)}$, both in developed and developing countries. Children are negatively affected by $\mathrm{HFI}^{(6,7)}$ as it has been associated with a higher prevalence of hospitalization, respiratory infection, fever, diarrhoea, and nutritional deficiencies such as Fe deficiency and other forms of malnutrition compared with children living in food-secure households $^{(8-10)}$.

Food deprivation and poor dietary quality in childhood influence children's growth, psycho-emotional, social and cognitive development, and overall health ${ }^{(11,12)}$. According to the 2006 Brazilian Demographic and Health Survey (DHS), only $57 \%$ of 12 - to 18 month-old children ate fruits and vegetables and $25 \%$ ate meat on a daily basis ${ }^{(3)}$. In Brazil, $7 \%$ of children suffer from chronic malnutrition (height-for-age $Z$-score (HAZ) $<-2)^{(3)}$; additionally, $1.6 \%$ of deaths of children under 5 years old are caused by acute diarrhoea and $5 \cdot 3 \%$ by acute respiratory infection ${ }^{(13)}$. 
Although the influence of HFI on dietary intake has been investigated in the last few years in Brazil and elsewhere $^{(14-16)}$, the association between HFI and common childhood infectious diseases needs more investigation $^{(10)}$. Thus, our study aimed to identify the independent association of HFI with the risk of vitamin A deficiency and anaemia, morbidities such as cough and fever, and hospitalizations for diarrhoea and pneumonia in children under 5 years old.

\section{Methods}

We analysed data from the 2006 Brazilian DHS, which is a nationally representative cross-sectional survey with complex probability sampling that covered rural and urban areas of each of the five Brazilian geographic regions. This survey was approved by the Research Ethics Committee of the Sexually Transmitted Diseases/AIDS Reference and Training Center of the São Paulo State Department of Health.

The process of sample selection for the 2006 Brazilian DHS has been described in detail elsewhere ${ }^{(3)}$. Briefly, participating households were selected in two stages, with the first being the selection of census tracts (primary sampling units) and the second the selection of households within each tract (secondary sampling units). A total of 14617 households were eligible for the survey. The target population of the survey was women of reproductive age (15-49 years) and their children living in the selected households. The survey interviewed 15468 women and collected data on 5461 children up to 59 months of age.

Our study focused on children under 5 years old. In our study, households were excluded if the target children had died before the interview, did not live with their mother (because HFI is assessed within households and the available HFI data refer to the mother's household), had missing HFI or anthropometric data, or had implausible anthropometric data (nutritional status $Z$-scores $<-4$ or $>+4$ ). Our analytical sample included 4064 children living in 3375 households.

In the 2006 Brazilian DHS, three finger-prick blood samples were collected from a sub-sample of children under 5 years ( $n$ 3499) on to filter paper. Of the 4064 children selected for the present study, 3425 and 3361 had retinol and $\mathrm{Hb}$ levels available, respectively. $\mathrm{Hb}$ and retinol concentrations were measured by the cyanmethaemoglobin method and HPLC, respectively, using the dried-drop technique ${ }^{(3)}$. Children with $\mathrm{Hb}$ levels below $110 \mathrm{~g} / \mathrm{l}$ were considered anaemic ${ }^{(17)}$. Vitamin A deficiency was defined as vitamin A levels below $0 \cdot 70 \mu \mathrm{mol} / \mathrm{l}^{(18)}$. Child anthropometric status was assessed using the indices HAZ, weight-for-age $Z$-score (WAZ) and weight-for-height $Z$-score (WHZ). Children were considered stunted or wasted when HAZ or WAZ was $<-2$ and overweight-for-height when WHZ was $>+2^{(19)}$. The DHS also investigated household conditions, such as source of water consumption, quality of sanitation, location (urban or rural), Brazil's geographical region (North, Northeast, Southeast, South, Middle-West) and maternal characteristics (age and educational level).

Food security status was measured using the fourteenitem Brazilian Household Food Insecurity Measurement Scale (Escala Brasileira de Insegurança Alimentar, EBIA $)^{(20)}$. Based on the HFI additive score, obtained from the number of affirmative answers to EBIA questions, as recommended households were classified into: food secure (score $=0$ ), mildly food insecure (score $=1$ to 5 ), moderately food insecure (score $=6$ to 9 ) and severely food insecure (score $=10$ to 14 ).

Child morbidity data were reported by the children's mothers to capture the occurrence of cough and fever in the last two weeks before the survey and hospitalizations for diarrhoea and pneumonia during the year prior to the survey.

Statistical analyses were performed with the statistical software package IBM SPSS Statistics Version 20.0 using the Complex Samples add-on module that computes estimates considering the complex sampling survey design. Chi-square bivariate and logistic regression analyses were conducted. Adjusted odds ratios and their corresponding $95 \%$ confidence intervals were estimated by adjusting for child anthropometric status (except for the stunting, wasting and overweight models), source of water consumption in the household, quality of household sanitation, maternal education level, maternal age and household location (rural/urban). Analyses were also adjusted for Brazilian regions to take regional socio-economic and food insecurity contextual factors into account ${ }^{(21)}$. Based on the pattern of bivariate associations, multivariate analyses were conducted using two HFI categories (severe HFI $v$. food secure/mild and moderate HFI).

\section{Results}

Of the children under 5 years old assessed in the present study, $6.7 \%$ lived in households experiencing severe HFI, $18.8 \%$ had vitamin A deficiency and $22.0 \%$ had anaemia. With regard to common childhood morbidities, $36.4 \%$ of the children were reported to have experienced cough and $23.7 \%$ fever during the two weeks preceding the survey. Additionally, $2.6 \%$ of them were hospitalized for diarrhoea or pneumonia in the year prior to the survey. Among the children suffering from malnutrition, $6 \cdot 8 \%$ were stunted and $6.9 \%$ had a high WHZ, indicating overweight-for-height (Table 1).

The prevalence of cough was significantly higher in children living in severely food-insecure households (Table 2). A similar result was also found for hospitalization for diarrhoea. The difference in the prevalence of 
Table 1 Characteristics of households and children under 5 years of age whose 15-49-year-old mothers were interviewed in the 2006 Brazilian Demographic and Health Survey. Brazil, 2006

\begin{tabular}{|c|c|c|c|}
\hline Household characteristic & $n$ & $\%$ & $95 \% \mathrm{Cl}$ \\
\hline \multicolumn{4}{|l|}{ Region } \\
\hline North & 896 & $10 \cdot 5$ & $9 \cdot 1,12 \cdot 0$ \\
\hline Northeast & 798 & $28 \cdot 0$ & $24 \cdot 7,31 \cdot 6$ \\
\hline Southeast & 817 & 41.9 & $37 \cdot 6,46 \cdot 3$ \\
\hline South & 749 & $12 \cdot 2$ & $10 \cdot 7,13 \cdot 8$ \\
\hline Middle-West & 804 & 7.5 & $6.5,8.6$ \\
\hline \multicolumn{4}{|l|}{ Household location } \\
\hline Urban & 2683 & $81 \cdot 2$ & $78 \cdot 2,83.9$ \\
\hline Rural & 1381 & 18.8 & $16 \cdot 1,21 \cdot 8$ \\
\hline \multicolumn{4}{|l|}{ Food security status } \\
\hline Food security & 2040 & $52 \cdot 7$ & $49 \cdot 0,56 \cdot 4$ \\
\hline Mild food insecurity & 1114 & $28 \cdot 0$ & $25 \cdot 2,31 \cdot 0$ \\
\hline Moderate food insecurity & 502 & $12 \cdot 6$ & $10.6,14.9$ \\
\hline Severe food insecurity & 408 & $6 \cdot 7$ & $5 \cdot 6,8 \cdot 1$ \\
\hline \multicolumn{4}{|l|}{ Child's health status } \\
\hline \multicolumn{4}{|l|}{ Vitamin A deficiency* } \\
\hline No & 2919 & $81 \cdot 2$ & $78 \cdot 2,83 \cdot 9$ \\
\hline Yes & 506 & 18.8 & $16 \cdot 1,21 \cdot 8$ \\
\hline \multicolumn{4}{|l|}{ Anaemia } \\
\hline No & 2778 & $78 \cdot 0$ & $74 \cdot 5,81 \cdot 1$ \\
\hline Yes & 583 & $22 \cdot 0$ & $18.9,25.5$ \\
\hline \multicolumn{4}{|l|}{ Cough $\ddagger$} \\
\hline No & 2576 & 63.3 & $60 \cdot 6,66 \cdot 5$ \\
\hline Yes & 1488 & $36 \cdot 4$ & $33.5,39.4$ \\
\hline \multicolumn{4}{|l|}{ Fever $\ddagger$} \\
\hline No & 3105 & $76 \cdot 3$ & $73.8,78.5$ \\
\hline Yes & 959 & 23.7 & $21 \cdot 5,26 \cdot 2$ \\
\hline \multicolumn{4}{|c|}{ Hospitalization for diarrhoea§ } \\
\hline No & 3954 & 97.4 & $97 \cdot 0,98 \cdot 3$ \\
\hline Yes & 110 & $2 \cdot 6$ & $1 \cdot 7,3 \cdot 0$ \\
\hline \multicolumn{4}{|c|}{ Hospitalization for pneumonia§ } \\
\hline No & 3954 & 97.4 & $96 \cdot 2,98 \cdot 2$ \\
\hline Yes & 110 & 2.6 & $1 \cdot 8,3 \cdot 8$ \\
\hline \multicolumn{4}{|l|}{ Nutritional status } \\
\hline Stuntingll & 350 & $6 \cdot 8$ & $5.5,8.4$ \\
\hline Wasting & 50 & $1 \cdot 3$ & $0 \cdot 8,2 \cdot 1$ \\
\hline Overweight-for-height** & 359 & 6.9 & $5 \cdot 8,8 \cdot 2$ \\
\hline Total & 4064 & $100 \cdot 0$ & - \\
\hline
\end{tabular}

*Vitamin A deficiency defined as retinol $<0.70 \mu \mathrm{mol} / \mathrm{l}(n$ 3425).

†Anaemia defined as $\mathrm{Hb}<110 \mathrm{~g} / \mathrm{d}(n$ 3361).

fln the last two weeks prior to the survey.

$\S$ In the last year prior to the survey.

IIHeight-for-age $Z$-score $<-2$ ( $n$ 4064).

TWeight-for-age $Z$-score $<-2$ ( $n$ 4064)

**Weight-for-height $Z$-score $>+2$ ( $n$ 4064).

vitamin A and anaemia between the categories of food insecurity and security was quite small and not statistically significant. A dose-response association was found between level of HFI severity and stunting. By contrast, high WHZ was more prevalent among children experiencing severe food insecurity compared with their food-secure counterparts.

The odds for cough, fever, and hospitalizations for diarrhoea and pneumonia were significantly higher in children living in severely food-insecure households (Table 3). For example, these children had 4.28 and 2.31 greater odds of being hospitalized for diarrhoea and pneumonia, respectively, compared with those living in food-secure households. After adjusting for confounders, strong and significant associations remained between severe HFI and the prevalence of cough (adjusted OR =1.67) and hospitalization for diarrhoea (adjusted OR $=2 \cdot 93$ ).

\section{Discussion}

Bivariate results of the present study show that, in Brazil, HFI is associated with stunting and the occurrence of common childhood illnesses. This is consistent with what has been reported in other countries ${ }^{(10,15,22)}$. Our findings on HFI and malnutrition in the context of the nutrition transition are in agreement with previous studies focusing on both child undernutrition $^{(7,23,24)}$ and overweight ${ }^{(25-28)}$. In our study, bivariate analyses showed that severely foodinsecure children had a higher prevalence of stunting and overweight compared with food-secure children. This is indeed what would be expected in the context of the nutrition transition in an upper middle-income country ${ }^{(29)}$. A study conducted in Colombia revealed that food-insecure children were three times more likely to be underweight, but not stunted, than food-secure children ${ }^{(30)}$. However, other studies have identified a dose-response relationship between HFI severity and the risk of child stunting ${ }^{(23,24,31)}$. In our study we found a similar prevalence of overweight between children living in food-secure, mildly and moderately food-insecure households. The higher prevalence of overweight in severely food-insecure children (7.1\%) in our study may be partially explained by poor dietary quality resulting from the hyperenergetic diet to which these children are exposed. Individuals living in food-insecure households have a lower intake of animal protein ${ }^{(30)}$ and higher intakes of snack foods ${ }^{(32,33)}$ and high-energy-density foods, because of the cost of these products ${ }^{(34,35)}$.

There have also been previous reports on the association between HFI and child overweight and obesity ${ }^{(36)}$; however, we could not confirm this association in our study. In agreement with previous studies ${ }^{(37,38)}$ our results did not confirm an association of HFI with anaemia and vitamin A deficiency. Micronutrient deficiencies, as well as excess weight, are related to poor dietary quality ${ }^{(8,30)}$ and reflect the effect of HFI on children's health in the context of poverty, low education, poor housing conditions and other vulnerabilities $^{(9,39)}$. In the case of Brazil as well as in other countries deeply immersed in the nutrition transition, it is possible that all social classes experience similar prevalence of micronutrient deficiencies as a result of well-established food fortification and supplementation programmes.

Our bivariate analyses showed that severely foodinsecure children were more likely to have experienced cough, fever, diarrhoea and pneumonia. This was expected, as higher morbidity rates have been observed previously among food-insecure children in other countries $^{(10,40,41)}$. Specifically, children living in food-insecure households are more susceptible to diarrhoea, respiratory infection and chronic diseases ${ }^{(9,23,42,43)}$. Child nutritional status has a close association with the occurrence of morbidities $^{(4)}$, as well as with income conditions and household characteristics such as location in the rural area and quality of sanitation ${ }^{(44)}$. These factors were also closely associated with diarrhoea in previous studies ${ }^{(44)}$. 
Table 2 Prevalence of morbidities and nutritional deficits, according to food security status, among 4064 children under 5 years of age whose 15-49-year-old mothers were interviewed in the 2006 Brazilian Demographic and Health Survey. Brazil, 2006

\begin{tabular}{|c|c|c|c|c|c|}
\hline Morbidity & $\begin{array}{c}\text { Food } \\
\text { security (\%) }\end{array}$ & $\begin{array}{c}\text { Mild food } \\
\text { insecurity (\%) }\end{array}$ & $\begin{array}{l}\text { Moderate food } \\
\text { insecurity (\%) }\end{array}$ & $\begin{array}{l}\text { Severe food } \\
\text { insecurity (\%) }\end{array}$ & $P$ value ${ }^{\star}$ \\
\hline \multicolumn{6}{|l|}{ Child's health status } \\
\hline \multicolumn{6}{|l|}{ Vitamin A deficiency $\dagger$} \\
\hline Yes & $18 \cdot 2$ & 22.4 & $13 \cdot 1$ & $20 \cdot 0$ & 0.092 \\
\hline \multicolumn{6}{|l|}{ Anaemiał } \\
\hline Yes & 21.4 & 23.5 & $19 \cdot 4$ & 24.9 & 0.674 \\
\hline \multicolumn{6}{|l|}{ Cough§ } \\
\hline Yes & $33 \cdot 2$ & 39.5 & $35 \cdot 8$ & $49 \cdot 6$ & 0.014 \\
\hline \multicolumn{6}{|l|}{ Fever§ } \\
\hline Yes & $23 \cdot 2$ & $23 \cdot 0$ & $23 \cdot 6$ & $31 \cdot 2$ & 0.299 \\
\hline \multicolumn{6}{|l|}{ Hospitalization for diarrhoeall } \\
\hline Yes & 1.8 & 1.8 & $2 \cdot 2$ & 7.6 & $<0.001$ \\
\hline \multicolumn{6}{|l|}{ Hospitalization for pneumoniall } \\
\hline Yes & $2 \cdot 1$ & $2 \cdot 4$ & 3.6 & 5.4 & 0.248 \\
\hline \multicolumn{6}{|l|}{ Nutritional status } \\
\hline Stunting & 5.5 & $7 \cdot 3$ & 8.9 & $11 \cdot 6$ & 0.042 \\
\hline Wasting ${ }^{\star \star}$ & 1.6 & 0.9 & 1.3 & 0.9 & 0.697 \\
\hline Overweight-for-height †† & $6 \cdot 7$ & $7 \cdot 8$ & $5 \cdot 4$ & $7 \cdot 1$ & 0.712 \\
\hline
\end{tabular}

*Using the $\chi^{2}$ test.

†Vitamin A deficiency defined as retinol $<0.70 \mu \mathrm{mol} / \mathrm{l}$ ( $n$ 3425).

$\ddagger$ Anaemia defined as $\mathrm{Hb}<110 \mathrm{~g} / \mathrm{d}(n 3361)$.

$\S$ In the last two weeks prior to the survey.

IIIn the last year prior to the survey.

\Height-for-age Z-score $<-2$.

${ }^{*}$ Weight-for-age $Z$-score $<-2$.

$\dagger+$ Weight-for-height $Z$-score $>+2$.

Table 3 Unadjusted and adjusted odds ratios for morbidities and nutritional deficits, according to food security status, among 4064 children under 5 years of age whose 15-49-year-old mothers were interviewed in the 2006 Brazilian Demographic and Health Survey. Brazil, 2006

\begin{tabular}{|c|c|c|c|}
\hline \multirow[b]{2}{*}{ Morbidity } & \multirow{2}{*}{$\begin{array}{l}\text { Other categories (food security }+ \text { mild and } \\
\text { moderate food insecurity) }\end{array}$} & \multicolumn{2}{|c|}{ Severe food insecurity } \\
\hline & & Unadjusted OR & $95 \% \mathrm{Cl}^{*}$ \\
\hline Cough in the last two weeks prior to the survey & 1 & 1.79 & $1.24,2.60$ \\
\hline Fever in the last two weeks prior to the survey & 1 & 1.50 & $1.01,2.22$ \\
\hline Hospitalizations for diarrhoea in the last year prior to the survey & 1 & 4.28 & $2.34,7.82$ \\
\hline Hospitalizations for pneumonia in the last year prior to the survey & 1 & 2.31 & $1.07,5.01$ \\
\hline Anaemia & 1 & 1.19 & $0.75,1.89$ \\
\hline Vitamin A deficiency & 1 & 1.09 & $0.70,1.68$ \\
\hline Stunting & 1 & 1.89 & $1.16,3.08$ \\
\hline \multirow[t]{2}{*}{ Overweight-for-height } & 1 & 1.03 & $0.45,2.40$ \\
\hline & & Adjusted OR & $95 \% \mathrm{Cl}$ \\
\hline Cough in the last two weeks prior to the survey* & 1 & 1.67 & $1 \cdot 14,2.46$ \\
\hline Fever in the last two weeks prior to the survey* & 1 & 1.30 & $0.84,1.99$ \\
\hline Hospitalization for diarrhoea in the last year prior to the survey* & 1 & 2.93 & $1.61,5.31$ \\
\hline Hospitalization for pneumonia in the last year prior to the survey ${ }^{\star}$ & 1 & 1.70 & $0.68,4.25$ \\
\hline Anaemia* & 1 & 1.57 & $0.94,2.60$ \\
\hline Vitamin A deficiency* & 1 & 1.45 & $0.88,2.37$ \\
\hline Stuntingt & 1 & 1.23 & $0.74,2.03$ \\
\hline Overweight-for-height $†$ & 1 & 1.34 & $0.55,3.26$ \\
\hline
\end{tabular}

*Adjusted by type of water for consumption, presence of adequate sanitation, maternal education level, maternal age, household location (urban or rural area), Brazilian geographic region and child's nutritional status.

†Adjusted by type of water for consumption, presence of adequate sanitation, maternal education level, maternal age, household location (urban or rural area) and Brazilian geographic region.

However, our findings clearly indicate that severe food insecurity remained strongly associated with the occurrence of hospitalization for diarrhoea after controlling for these key confounders. This confirms the previous conclusion that experience-based HFI scales such as EBIA indeed capture health risk information that goes well above and beyond what traditional socio-economic and demographic variables $\mathrm{do}^{(45)}$. In this context, it is worth emphasizing the importance of food insecurity (especially in its more severe form) as a strong risk factor for the occurrence of common childhood illnesses such as cough and diarrhoea among Brazilian children. Our study did not find any associations 
of morbidities, anthropometric status or micronutrient deficiencies with mild or moderate food insecurity. This was unexpected because dietary quality has been previously reported to be negatively affected by mild and moderate $\mathrm{HFI}^{(6,15,16)}$. This finding may be explained by strong improvements in the social determinants of health across social classes over the past decades ${ }^{(46)}$.

One limitation of our study is that we were able to adjust only for the factors likely to be involved in the association between childhood morbidity and HFI that were available from the 2006 DHS. For example, we did not have data on specific health literacy of the mother or health-care access issues affecting the child. A second limitation is that all data, including HFI and morbidity information, were reported by the mothers. However, previous research shows that EBIA has strong internal and external validity ${ }^{(47,48)}$ and that caregivers' report of child morbidity is reliable ${ }^{(49)}$. Further prospective studies are needed to better understand the actual role of HFI on the prevalence of childhood morbidity and to allow for a thorough investigation on the matter, including other socio-economic, health and food intake data.

\section{Conclusion}

In conclusion, severe HFI is associated with a higher risk of cough and hospitalization due to diarrhoea among Brazilian children under 5 years of age, illustrating the importance of linking better the food systems and the health-care systems in Brazil.

\section{Acknowledgements}

Financial support: This work was supported by funding from the National Council of Technological and Scientific Development (CNPq). CNPq had no role in the design, analysis or writing of this article. Conflict of interest: M.B.G., A.M.S., G.A.B. and R.P.-E. declare no conflicts of interest. Authorship: M.B.G. and R.P.-E. designed the research; M.B.G. and A.M.S. performed statistical analyses; R.P.-E. and G.A.B. supplied technical assistance and advice; M.B.G., A.M.S., G.A.B. and R.P.-E. wrote the paper and M.B.G. had primary responsibility for the final content. All authors read and approved the final manuscript. Ethics of human subject participation: This study was conducted according to the guidelines laid down in the Declaration of Helsinki and all procedures involving human subjects/patients were approved by the Research Ethics Committee of the Sexually Transmitted Diseases/AIDS Reference and Training Center of the São Paulo State Department of Health.

\section{References}

1. United Nations World Food Programme (2015) Food security analysis. http://www.wfp.org/food-security (accessed September 2015).
2. Food and Agriculture Organization of the United Nations (2015) The State of Food Insecurity in the World. Meeting the 2015 International Hunger Targets: Taking Stock of Uneven Progress. Rome: FAO.

3. Brasil Ministério da Saúde (2009) Pesquisa Nacional de Demografia e Saúde da Criança e da Mulher - DHS 2006: Dimensões do Processo Reprodutivo e da Saúde da Criança. Brasília: MS.

4. Addo AA, Marquis GS, Lartey AA et al. (2011) Food insecurity and perceived stress but not HIV infection are independently associated with lower energy intakes among lactating Ghanaian women. Matern Child Nutr $\mathbf{7}$, 80-91.

5. Stuff JE, Casey PH, Szeto KL et al. (2004) Household food insecurity is associated with adult health status. J Nutr 134, 2330-2335.

6. Saha KK, Frongillo EA, Alam DS et al. (2008) Household food security is associated with infant feeding practices in rural Bangladesh. J Nutr 138, 1383-1390.

7. Monteiro F, Schmidt ST, Costa IB et al. (2014) Bolsa Família: insegurança alimentar e nutricional de crianças menores de cinco anos. Cienc Saude Colet 19, 1347-1358.

8. Cook JT, Frank DA, Berkowitz C et al. (2004) Food insecurity is associated with adverse health outcomes among human infants and toddlers. $J$ Nutr 134, $1432-1438$.

9. Skalicky A, Meyers AF, Adams WG et al. (2006) Child food insecurity and iron deficiency anaemia in low-income infants and toddlers in the United States. Matern Child Health J 10, 1177-1185.

10. Ohemeng A, Marquis GS \& Lartey A (2015) Household food insecurity is associated with respiratory infections among 6- to 11-month old infants in rural Ghana. Pediatr Infect Dis J 34, 821-825.

11. Perez-Escamilla R \& Vianna RPT (2012) Food insecurity and the behavioral and intellectual development of children: a review of the evidence. J Appl Res Child 3, 1.

12. Perez-Escamilla R (2013) Food insecurity in children: impact on physical, psychoemotional and social development. In Modern Nutrition in Health and Disease, 11th ed., pp. 1006-1015 [CA Ross, B Caballero, RJ Cousins et al., editors]. Baltimore, MD: Lippincott Williams \& Wilkins.

13. Brasil Ministério da Saude (2012) Rede Intergerencial de Informações para a Saúde (RIPSA) Indicadores e Dados Básicos para a Saúde. http://tabnet.datasus.gov.br/cgi/ idb2012/matriz.htm\#mort (accessed May 2015).

14. Morais DC, Dutra LV, Franceschini SCC et al. (2014) Food insecurity and anthropometric, dietary and social indicators in Brazilian studies: a systematic review. Cienc Saude Colet 19, $1475-1488$.

15. Ghattas H (2014) Food Security and Nutrition in the Context of the Nutrition Transition. Technical Paper. Beirut: American University of Beirut; available at http:// www.fao.org/economic/ess/essfs/voices/en/

16. Rosas LG, Harley K, Fernald LC et al. (2009) Dietary associations of household food insecurity among children of Mexican descent: results of a binational study. J Am Diet Assoc 109, 2001-2009.

17. World Health Organization (2001) Iron Deficiency Anaemia: Assessment, Prevention, and Control: A Guide for Programme Managers. Geneva: WHO.

18. World Health Organization (1996) Indicators for Assessing Vitamin A Deficiency and Their Application in Monitoring and Evaluating Intervention Programmes. Geneva: WHO.

19. World Health Organization (2006) WHO Child Growth Standards based on length/height, weight and age. Acta Paediatr Suppl 450, 76-85.

20. Brasil Instituto Brasileiro de Geografia e Estatística (2014) Pesquisa Nacional por Amostra de Domicílios - PNAD. Segurança Alimentar 2013. Rio de Janeiro: IBGE. 
21. Gubert MB, Benício, MHD \& Santos LMP (2010) Estimativas de insegurança alimentar grave nos municípios brasileiros. Cad Saude Publica 26, 1595-1605.

22. Garrett JL \& Ruel MT (2003) Stunted Child-Overweight Mother Pairs: An Emergency Policy Concern? FCND Discussion Paper no. 148. Washington, DC: International Food Policy Research Institute.

23. Hackett M, Melgar-Quiñone H \& Álvarez MC (2009) Household food insecurity associated with stunting and underweight among preschool children in Antioquia, Colombia. Rev Panam Salud Publica 25, 506-510.

24. Saaka M \& Osman SM (2013) Does household food insecurity affect the nutritional status of preschool children aged 6-36 months? Int J Popul Res 2013, 304169.

25. Casey PH, Szeto K, Lensing S et al. (2001) Children in foodinsufficient, low-income families: prevalence, health, and nutrition status. Arch Pediatr Adolesc Med 155, 508-514.

26. Casey PH, Simpson PM, Gossett JM et al. (2006) The association of child and household food insecurity with childhood overweight status. Pediatrics 118, e1406-e1413.

27. Eisenmann JC, Gundersen C, Lohman BJ et al. (2011) Is food insecurity related to overweight and obesity in children and adolescents? A summary of studies, 1995-2009. Obes Rev 12, 73-83.

28. Franklin B, Jones A, Love D et al. (2012) Exploring mediators of food insecurity and obesity: a review of recent literature. J Community Health 37, 253-264.

29. Kac G \& Pérez-Escamilla R (2013) Nutrition transition and obesity prevention through the life-course. Int J Obes Suppl 3, S6-S8.

30. Isanaka S, Mora-Plazas M, Lopez-Arana S et al. (2007) Food insecurity is highly prevalent and predicts underweight but not overweight in adults and school children from Bogotá, Colombia. J Nutr 137, 2747-2755.

31. Shamah-Levy T, Mundo-Rosas V \& Rivera-Dommarco JA (2014) Magnitude of food insecurity in Mexico: its relationship with nutritional status and socioeconomic factors. Salud Publica Mex 56, Suppl. 1, S79-S85.

32. Kaiser LL, Melgar-Quinonez H, Townsend MS et al. (2003) Food insecurity and food supplies in Latino households with young children. J Nutr Educ Behav 35, 148-153.

33. Perez-Escamilla R, Segall-Correa AM, Kurdian Maranha L et al. (2004) An adapted version of the US Department of Agriculture food insecurity module is a valid tool for assessing household food insecurity in Campinas, Brazil. J Nutr 134, 1923-1928.

34. Drewnowski A \& Specter SE (2004) Poverty and obesity: the role of energy density and energy costs. Am J Clin Nutr $\mathbf{7 9}$, 6-16.

35. Drewnowski A, Monsivais P, Maillot M et al. (2007) Lowenergy-density diets are associated with higher diet quality and higher diet costs in French adults. J Am Diet Assoc 107 1028-1032.
36. Sharkey JR, Nalty C, Johnson CM et al. (2012) Children's very low food security is associated with increased dietary intakes in energy, fat, and added sugar among Mexicanorigin children (6-11 y) in Texas border Colonias. BMC Pediatrics 12, 16

37. Girard AW, Self JL, McAuliffe C et al. (2012) The effects of household food production strategies on the health and nutrition outcomes of women and young children: a systematic review. Paediatr Perinat Epidemiol 26, Suppl. 1, 205-222.

38. Rodrigues LPF \& Roncada MJ (2010) Nutrition education in the official programs for preventing vitamin A deficiency in Brazil. Rev Nutr 23, 297-305.

39. Park K, Kersey M, Geppert J et al. (2009) Household food insecurity is a risk factor for iron-deficiency anaemia in a multi-ethnic, low-income sample of infants and toddlers. Public Health Nutr 12, 2120-2128.

40. Cook JT, Frank DA, Levenson SM et al. (2006) Child food insecurity increases risks posed by household food insecurity to young children's health. J Nutr 136, 1073-1076.

41. Cook JT, Frank DA, Casey PH et al. (2008) A brief indicator of household energy security: associations with food security, child health, and child development in US infants and toddlers. Pediatrics 122, 867-875.

42. Nord M (2009) Food Insecurity in Households with Children: Prevalence, Severity, and Household Characteristics. Economic Information Bulletin no. EIB-56. Washington, DC: US Department of Agriculture, Economic Research Service.

43. Reis M (2012) Food insecurity and the relationship between household income and children's health and nutrition in Brazil. Health Econ 21, 405-427.

44. Black RE, Allen LH, Bhutta ZA et al. (2008) Maternal and Child Nutrition 1: Maternal and child undernutrition: global and regional exposures and health consequences. Lancet 371, 243-260

45. Pérez-Escamilla R (2012) Can experience-based household food security scales help improve food security governance? Glob Food Sec 1, 120-125.

46. Monteiro CA, Benicio AMH, Konno SC et al. (2009) Causes for the decline in child undernutrition in Brazil, 1996-2007. Rev Saude Publica 43, 35-43.

47. Segall-Corrêa AM \& Marin-León L (2009) A Segurança Alimentar no Brasil: Proposição e Usos da Escala Brasileira de Medida da Insegurança Alimentar (EBIA) de 2003 a 2009. Seg Aliment Nutr Campinas 16, issue 2, 1-19.

48. Segall-Corrêa AM, Marin-León L, Melgar-Quiñonez H et al. (2014) Refinement of the Brazilian Household Food Insecurity Measurement Scale: recommendation for a 14-item EBIA. Rev Nutr 27, 241-251.

49. Rousham EK, Northrop-Clewes CA \& Lunn PG (1998) Maternal reports of child illness and the biochemical status of the child: the use of morbidity interviews in rural Bangladesh. Br J Nutr 80, 451-456. 